\title{
Las relaciones internacionales y la conmemoración del Primer Centenario de la Independencia en el Ecuador, 1909. Entre las reformas liberales y las colonialidades
}

\author{
Gerson Galo Ledezma Meneses*
}

\section{RESUMEN}

Basados en fuentes documentales, como libros y prensa, publicadas en la época del I Centenario de la Independencia en Ecuador, constatamos que a la Exposición Nacional realizada en Quito, en 1909, fueron invitados varios países, de los cuales comparecieron España, Francia, Estados Unidos, Perú, Colombia y Chile, entre otros. Pretendemos verificar los intereses que tuvieron esas naciones al presentarse en la conmemoración y cuáles fueron los objetivos del país andino al invitarlos. Destacamos la presencia de Espańa y la forma cómo su reconquista cultural sobre el país, así como de otros de América Latina, habría influido en la guerra que la sociedad ecuatoriana enprendió contra las reformas liberales de Eloy Alfaro.

Palabras clave: Relaciones internacionales; Ecuador; Centenario de la Independencia.

\section{RESUMO}

Com base em fontes documentais, como livros e jornais, publicadas na época do I Centenário da Independência do Equador, constatamos que vários países foram convidados à Exposiçáo Nacional realizada em Quito, em 1909. Entre os que aceitaram o convite, participaram Espanha, França, Estados Unidos, Peru, Colômbia e Chile. Este estudo procura verificar quais os interesses dessas naçóes para estar na comemoração e quais os objetivos do país andino para convidá-las. Destacamos a presença da Espanha e a forma como a sua reconquista cultural do Equador, bem como de outros países na América Latina, teria influenciado a guerra da sociedade equatoriana contra as reformas liberais de Eloy Alfaro.

Palavras-chave: relações internacionais; Equador; Centenário da Independência.

\section{ABSTRACT}

Sources such as books and newspapers published at the time of the I Independence

DOI - http://dx.doi.org/10.1590/2237-101X01803504

Artigo recebido em 24 de setembro de 2016 e aprovado para a publicaçáo em 9 de março de 2017.

* Professor da Universidade Federal da Integração Latino-americana. Foz do Iguaçu-PR, Brasil. E-mail: gersonledezma@yahoo.com.br. 
Centennial of Ecuador, in 1909, reveal that several countries were invited to the National Exhibition then organized in Quito. Among others, Spain, France, United States, Peru, Colombia and Chile accepted the invitation. This study examines the reasons that moved Ecuador to invite those countries, and why did they accept the invitation. We emphasize the presence of Spain, and how its cultural recapture of Ecuador, as well as of other Latin-American countries, might have influenced the war that the Ecuadorian society waged against the liberal reforms of Eloy Alfaro.

Keywords: International Relations; Ecuador; Independence Centennial.

\section{Introducción}

Uno de los eventos que marcó la celebración del Centenario de la Independencia en 1909 en Ecuador, especialmente en Quito, fue la Exposición Nacional, la cual mostró tecnologías, artesanías, artículos, flora y fauna locales e internacionales, contando con la presencia de Estados Unidos, Francia, Bélgica, Japón, Espańa, Italia, Colombia, Chile y Perú. Nos interesa mostrar algunas de las razones que llevaron a estos países a participar de la fiesta centenaria, y los intereses que Ecuador ofrecía, en esa coyuntura especial, a los Estados-nación que aceptaron la invitación. Destacamos la presencia de España y su proyecto de reconquista cultural de América Latina, y de Ecuador, en este caso. Influencia conservadora que nos ayuda a entender la reacción negativa de la sociedad ecuatoriana, frente a las reformas liberales del presidente Eloy Alfaro.

Algunas de las categorías conceptuales que iluminaron el análissis del tema aquí tratado provienen de la perspectiva de la historia de las relaciones internacionales: fuerzas profundas, fueron las palabras acuñadas por Pierre Renouvin y Jean-Baptiste Duroselle. Este concepto fue propuesto con el objetivo de aprehender el fenómeno internacional en un radio más amplio. Este concepto no supone una relegación del rol del Estado, como único actor que conduciría la política exterior; nos induce a verificar, no sólo las relaciones entre Estados nación, a partir de la documentación exclusiva de las cancillerías, sino también a los "hombres" de Estado, las colectividades, sus sicologías colectivas, entre otras tramas de la historia. De esa forma, Renouvin \& Duroselle proceden a considerar también las condiciones geográficas, los movimientos demográficos, los intereses económicos y financieros, las grandes corrientes sentimentales, que muestran las fuerzas profundas que han formado el marco de las relaciones entre grupos humanos y que, en gran medida, han determinado su naturaleza. ${ }^{1}$

${ }^{1}$ DUROSELLE, Jean-Baptiste. Todo império perecerá. Teoria das relaçôes internacionais. Tradução de Ane Lize Spaltemberg de Seiqueira Magalhães. Brasília: Edunb, 2000. RENOUVIN, Pierre; DUROSELLE, 
Las RelaCiones internacionales y la CONMEMoración del Primer Centenario de la Independencia en el ECUADOR, I 909. ENTRE LAS REFORMAS LIBERALES Y LAS COLONIALIDADES

El artículo se basa en fuentes primarias y secundarias; damos importancia a periódicos de la época de la conmemoración del Primer Centenario de la Independencia, 1909, tales como El Ecuatoriano, de Guayaquil, La Prensa, de Quito y, principalmente, El Comercio, también de la capital ecuatoriana. Este periódico aparece, por primera vez, bajo la bandera de ser el primer periódico independiente, al no tener una clara tendencia política, ni liberal ni conservadora, sin disimular su postura antialfarista. Aunque el primer ejemplar del diario fue publicado el $1^{\circ}$ de enero de 1906, la historia de este emblemático periódico empieza un año antes. En enero de 1905, los hermanos César y Carlos Mantilla Jácome mantuvieron una reunión con el periodista Celiano Monge para contarle sus deseos de crear un periódico serio e independiente de los partidos políticos. En su primer día de circulación, un conjunto de eventos culminaron con un golpe militar que encerró el gobierno del presidente Lizardo García por parte del General Eloy Alfaro, por lo que los accionistas pararon la producción del diario, y la segunda edición fue publicada dos meses después. El diario circuló ininterrumpidamente bajo el lema "Diario Independiente" hasta enero de 1908 cuando por disposición del Presidente Alfaro, en medio de un ambiente tenso entre la prensa y el gobierno, El Comercio cerró por dos semanas. ${ }^{2}$ Se acercaba la fecha del Primer Centenario de la Independencia, 10 de agosto de 1909. Así mismo, recurrimos a fuentes bibliográficas publicadas en la primera década del siglo XX, dedicadas a la investigación de los diferentes litigios fronterizos entre los países de América del Sur, especialmente los que envolvían directamente a Ecuador y los vecinos.

\section{Las reformas liberales y la continuación de la misma mentalidad colonial}

El clima de la conmemoración de la fiesta del Primer Centenario de la Independencia de Ecuador se da en un período de transición entre el período criollo de proyecto nacional para el mestizo. ${ }^{3}$ El sostenido incremento de la exportación cacaotera en la costa y el comercio de importaciones trajeron consigo un proceso de acumulación cada vez más significativo del capital, consolidándose así el predominio de los sectores capitalistas dinámicos de la economía; se definió el modelo primario de agroexportación y se formó una burguesía comercial y bancaria, el sector que estuvo al frente de la llamada revolución liberal comandada por Eloy Alfaro, después del golpe de Estado y guerra civil de 1895; época de consolidación del Estado nacional. ${ }^{4}$

Jean-Baptiste. Introducción a la historia de las relaciones internacionales. Madrid: FCE, 2000.

${ }^{2}$ RIVADENEIRA MORENO, Katerine Elisa. Monitoreo de editoriales y artículos de opinión y la imagen que proyectan del presidente Rafael Correa. Estudio de caso: Diario El Comercio Abril 2009. Tesis (Licenciada en Comunicación Social) —Universidad Politécnica Salesiana, Sede Quito, 2013.

3 Periodización propuesta por AYALA MORA, Enrique. Historia, tiempo y conocimiento del pasado. Estudio sobre periodización general de la historia ecuatoriana: una interpretación interparadigmática. Quito: Universidad Andina Simón Bolívar, 2014.

${ }^{4}$ AYALA MORA, Enrique. Resumen de historia del Ecuador. 4. ed. Quito: Corporación Editora Nacional/ 
Las relaciones internacionales y la CONMEMoración del Primer Centenario de la Independencia en el ECUADOR, I 909. ENTRE LAS REFORMAS LIBERALES Y LAS COLONIALIDADES

José Eloy Alfaro ocupó la presidencia del Ecuador en dos oportunidades, 18971901 y 1906-1911; dio paso a la transformación liberal que iniciada en 1895 se extiende hasta 1924. En el segundo mandato se promulgó la Constitución de 1906, "la carta magna del liberalismo ecuatoriano". El "Decálogo Liberal" de los radicales ecuatorianos, publicado en aquella época, proponía: Decreto de manos muertas; supresión de conventos; supresión de monasterios; enseñanza laica y obligatoria; libertad de los indios; abolición del Concordato; secularización eclesiástica; expulsión del clero extranjero; Ejército fuerte y bien remunerado; Ferrocarril al Pacífico. También creó la nueva institucionalidad civil con el Registro Civil, la Asistencia Pública, las oficinas de telégrafos, algunas de salud e incluso nuevos ministerios. Se incluyeron leyes civiles, como la de Cultos, Matrimonio civil y Divorcios. ${ }^{5}$

Además de dar pasos hacia cambios en la vida de mujeres de elite principalmente, Eloy Alfaro, obedeciendo a designios del sistema-mundo capitalista, planeó liberar la mano de obra sujeta a la hacienda andina para incorporarla a la costera, bajo control de hacendados del cacao de la provincia de Guayas. Las mujeres ocuparían otros espacios, pero ellas, como los indígenas sólo cambiarían de local de explotación; no hubo interés por parte de la elite para, por medio de las leyes alfaristas, hacer una crítica al modelo de sociedad que continuaba racializando y discriminando a estos sectores para dominarlos mejor. En esta época del Centenario, llegaban de Europa las supuestas pruebas, ahora científicas, de que negros e indios eran inferiores racialmente. En el mundo de la Sierra los hacendados andinos quedarían maniatados, sin su contingente servil de "toda la vida". Una vez que esas medidas surtieron efecto, los peones quedaron libres para seguir el camino de los Andes hacia la costa, rumbo al sórdido trabajo de las haciendas tipo exportación y las fábricas del mundo industrial de ciudades como Guayaquil.

Ayala Mora afirma que la Revolución Liberal significó un gran salto, pues el predominio político e ideológico del latifundismo clerical fue desmontado por la burguesía y sus aliados, pero no pudo desmontar la estructura latifundista de la Sierra, ni abolir el poder regional terrateniente. El latifundismo derrotado, pero no destruido, cerró filas con la Iglesia. Así, el conflicto se daría entre el Estado liberal y la Iglesia católica, dirigida por el clero y la vieja aristocracia, respaldados por sectores artesanales organizados. Al final, concluye Ayala Mora, las transformaciones implantadas por el liberalismo, fueron innovaciones políticas e ideológicas, orientadas a consolidar mecanismos de reproducción del sistema capitalista en ascenso. Con ellas, la burguesía aseguró su control del Estado, garantizando condiciones

Universidad Andina Simón Bolívar, 2012.

${ }^{5}$ Sobre las reformas liberales y el período alfarista se pueden consultar varias obras, entre las cuales, AYALA MORA, Enrique. De la revolución alfarista al régimen oligárquico liberal, 1895-1925. En: AYALA MORA, Enrique. Nueva Historia del Ecuador (Editor), v. 9. Quito. CEN-Grijalbo, 1988; del mismo autor: Resumen de historia del Ecuador, op. cit. CUEVA, Agustín. El processo de dominación politica en Ecuador. Quito: Voluntad, 1973. ALBORNOZ PERALTA, Oswaldo. Ecuador: luces y sombras del liberalismo. Quito: El Duende, 1989. HURTADO, Oswaldo. El poder político en el Ecuador. 17. ed. Quito: Planeta, 2007. PAREJA DIEZCANSECO, Alfredo. Breve historia del Ecuador. Quito: Libresa, 1994. 
Las relaciones internacionales y la CONMEMoración del Primer Centenario de la Independencia en el ECUADOR, I 909. ENTRE LAS REFORMAS LIBERALES Y LAS COLONIALIDADES

\section{Gerson Galo Ledezma Meneses}

favorables a la integración de los mercados internos y a la vinculación cada vez más estrecha con el sistema internacional. ${ }^{6}$

En consecuencia , Ecuador impulsaría su proyecto de Estado nación, adhiriéndose al sistema-mundo capitalista/moderno/colonial/patriarcal,7 desde la perspectiva burguesa. Lugar desde donde continuaría perpetuando la misma mentalidad racista, machista, homofóbica y discriminadora social, aquello que Anibal Quijano define como colonialidad del poder. ${ }^{8}$ Sí el sistema-mundo capitalista ha sido definido como patriarcal, se debe admitir también su esencia machista y homofóbica. Recordemos que el capitalismo defiende el modelo de sociedad heteronormativa desde su conformación al final de la Edad Media y después de la invasión ibérica a América en 1492. El capitalismo y su ética protestante contrubuyeron a afianzar la sociedad patriarcal. Así, desde el siglo XVI al XIX, Europa construyó un aparato de poder suficientemente estructurado para controlar el mundo en diversas áreas: económica, política y sociocultural. Este moderno sistema-mundo aportó a las ciencias sociales un nuevo modelo teórico-interpretativo. Concepto formulado por Immanuel Wallerstein en obras publicadas en 1974; 1980; 1989; ${ }^{9}$ el autor tuvo influencia de

\footnotetext{
${ }^{6}$ AYALA MORA, Enrique. Resumen de historia del Ecuador, op. cit., p. 93-96.

${ }^{7}$ Sistema-mundo capitalista es una categoría acuñada por varios autores que dan continuidad a la Teoría de la Dependencia, entre las décadas de 1970 y 1980. Para estos intelectuales no fue sólo el capitalismo que se implantó en el siglo XVI después de la invasión a América, sino un sistema que además de estar enganchado a la economía, lo está también a lo social, político y cultural; Europa se posiciona como centro y desarrolla todos los mecanismos para mantenerlo vigente. Entre estos intelectuales citamos principalmente a WALLERSTEIN, Immanuel. Análisis de Sistemas Mundo. Una Introducción. México: Siglo XXI, 2006. Sin embargo, teniendo encuenta que sí el sistema-mundo capitalista nace en el siglo XVI a través de la invasión y conquista de América, y si, según Enrique Dussel, la Modernidad da a luz en 1492, ese sistema no sería sólo capitalista, sino moderno y colonial, según lo define también Anibal Quijano. Por su parte, Ramón Grosfoguel lo denomina de patriarcal: sistema-mundo capitalista, moderno/colonial/patriarcal. Puede consultarse a: DUSSEL, Enrique. 1492: El encubrimiento del Otro. Hacia el origen del "mito de la Modernidad". La Paz: Facultad de Humanidades y Ciencias de la Educación/Plural Editores, 1994. QUIJANO, Aníbal. Colonialidad del poder y clasificación social. En: CASTRO-GÓMEZ, Santiago; GROSFOGUEL, Ramón (Ed.). El giro decolonial. Reflexiones para una diversidad epistémica más allá del capitalismo global. Bogotá: Siglo del Hombre Editores/Universidad Central/Instituto de Estudios Sociales Contemporáneos y Pontificia Universidad Javeriana/Instituto Pensar, 2007. GROSFOGUEL, Ramon. La descolonización de la economía politica. Cuaderno de Investigación. Bogotá: Universidad Libre, 2010.

${ }^{8}$ Entendemos con Aníbal Quijano la Colonialidad como uno de los elementos constitutivos y específicos del padrón mundial de poder capitalista. Se funda en la imposición de una clasificación racial/étnica de la población del mundo como una piedra angular del referido patrón de poder, y opera en cada uno de los planos, ámbitos y dimensiones, materiales y subjetivas de la existencia cotidiana y la escala social. Se origina y se mundializa a partir de América. Con la construcción de América en el mismo momento y en el mismo movimiento histórico, el emergente poder capitalista se vuelve mundial, sus centros hegemónicos se localizan en las zonas situadas en el Atlántico — que después se identificarán como Europa-, y como ejes centrales de su nuevo sistema de dominación se establecen también la colonialidad y la modernidad. Con América Latina, concluye Quijano, el capitalismo se hace mundial, eurocentrado y la colonialidad y la modernidad se instalan, hasta hoy, como los ejes constitutivos de este específico sistema de poder. QUIJANO, Aníbal. Colonialidad del poder y clasificación social, op. cit., p. 93-94.

${ }^{9}$ WALLERSTEIN, Immanuel. O sistema mundial moderno. V. II: o mercantilismo e a consolidação da
} 
Las relaciones internacionales y la CONMEMoración del Primer Centenario de la Independencia en el ECUADOR, I 909. ENTRE LAS REFORMAS LIBERALES Y LAS COLONIALIDADES

Marx, Braudel, la Teoría de la Dependencia y la experiencia práctica en África postcolonial; surgido en el siglo XVI, el sistema-mundo capitalista se consolida con el surgimiento de los imperios y los Estados nación.

Sí bien las estructuras capitalistas han ido transformándose a lo largo del tiempo, otras estructuras permanecen, tales como las mentalidades, pues como bien las catalogó Fernand Braudel, ellas son de larga duración; o como diría Anibal Quijano, colonilidades, especialmente las del poder. Giovanni Arrighi y Beverly Silver, defienden que el proceso de formación y expansión del capitalismo histórico no se dio por una trayectoria lineal dentro de estructuras inmutables y relaciones permanentes. Existe una dinámica con continuidades de estructuras y de relaciones — de allí la larga duración- y discontinuidades con innovaciones en las estructuras y con nuevas relaciones entre ellas - por eso, el cambio. A lo largo de la historia del capitalismo, hubo cambios sistemáticos, caracterizados por procesos de reorganización radical del moderno sistema-mundo, que alteraron substantivamente la naturaleza de los integrantes del sistema, su manera de relacionarse unos con los otros y el modo como el sistema funciona y se reproduce. ${ }^{10}$

El sistema-mundo capitalista se amplía a partir del siglo XIX y toma dimensiones impares. La llamada Paz de Vestfalia, de 1648, inauguró el moderno Sistema Internacional, al acatar consensualmente nociones y principios como el de soberanía estatal y el de Estado nación. Surgió, así, la noción embrionaria de que una paz duradera derivaba de un equilibrio de poder; la soberanía fue colocada en el orden del día hasta casi finalizar el siglo XVIII cuando Napoleón Bonaparte invadió diferentes territorios europeos, pasando por encima de los Tratados firmados en 1648 en Vestfalia. ${ }^{11}$ Hechos que obligaron a las potencias de la época: Rússia, Austria, Prusia e Inglaterra a convocar el Congreso de Viena entre 1814 y 1815, después de la caida de Napoleão. Francia, perdonada rapidamente, asistió al Congreso donde se estabelecieron las reglas del nuevo juego político y económico, juego de poder del nuevo orden mundial. En el siglo XIX, el sistema internacional se expandió de Europa para el mundo entero, bajo la forma de una red de integración comun tejida por un elemento cultural comun, llamado Sociedad Internacional Europea. Los europeos determinarán las relaciones con los nuevos Estados que ellos y sus descendientes crearon en América y después en África y Oceanía. E impusieron las mismas relaciones sobre el mundo musulmán y sobre el continente asiático. Al tornarse mundial, la sociedad internacional europea montó un efectivo sistema de dominación. La expansión europea era una iniciativa de Estados

economia-mundo europeia, 1600-1750. Porto: Afrontamentos, 1980. WALLERSTEIN, Immanuel. El moderno sistema mundial (III). La segunda era de gran expansión de la economía-mundo capitalista, 17301850. Madrid: Siglo XXI de España, 2010. WALLERSTEIN, Immanuel. O sistema mundial moderno. V. I: a agricultura capitalista e as origens da economia-mundo europeia no século XVI. Porto: Afrontamentos, 1974. 10 ARRIGHI, Giovanni; SILVER, Beverly. Caos e governabilidade no moderno sistema mundial. Rio de Janeiro: Contraponto/UFRJ, 2001, p. 30.

${ }^{11}$ ARRIGHI, Giovanni. O longo século XX: dinheiro, poder e as origens de nosso tempo. Rio de Janeiro: Contraponto; São Paulo: Unesp, 1995. 
Las relaciones internacionales y la CONMEMoración del Primer Centenario de la Independencia en el ECUADOR, I 909. ENTRE LAS REFORMAS LIBERALES Y LAS COLONIALIDADES

\section{Gerson Galo Ledezma Meneses}

y empresas que no actuaban con libertad total, pues se sometían a acuerdos colectivos o intervenciones por conveniencia según los padrones de conducta intereuropeos. ${ }^{12}$

En ese sentido, mientras Inglaterra abría puertos en diferentes partes del mundo, Francia expandía un proyecto civilizatorio que dictaba las normas en la arquitectura, en la música, artes, culinaria, en la forma de comportarse y de ser civilizado. Inglaterra y Francia intentarán imponer al mundo el modelo de Estado nación, sus formas de gobierno, las instituciones, los derechos humanos, en fin, lo que vendría a ser el paradigma de ciudadanía basado en un concepto de democracia liberal. Así, las nacientes naciones latinoamericanas acataron la propuesta de país vehiculado por la Hegemonía Colectiva.

Los países que formaban tal Colectivo eran los más racionales; inspirados en la razón, habían participado de la colonización de América; junto con España y Portugal habían desarrollado mecanismos de dominación que en el siglo XIX y XX fueron heredados por los incipientes Estados nación, como Ecuador que en la época de la conmemoración del Primer Centenario de la Independencia pretendía someter a las regiones y conectarse al sistema-mundo capitalista. De esa manera, el racismo, la discriminación social, las relaciones desiguales de género y la homofobia fueron camufladas en conceptos modernos como democracia, ciudadanía y clases sociales; esa estrategia beneficiaba a sectores blancos, o criollos, que habían realizado la Independencia, los mismos que determinarían quién podía o no hacer parte del nuevo sistema de poder llamado Estado nación.

Sí bien el Primer Centenario de la Independencia pudo ser aprovechado para reflexionar sobre la herencia colonial aún presente en 1909, este se prestó para celebrar la recolonización de Ecuador, principalmente desde la cultura y las mentalidades. ${ }^{13}$ Las colonialidades estaban presentes y se arraigaron aún más, o sufrieron una metamorfosis, pues de la elite terrateniente se extendieron a la elite burguesa. La presencia de Estado Unidos y de Francia se explica fácilmente, ya que en la medida en que el Estado nación ecuatoriano se va consolidando, necesitaba del apoyo del sistema-mundo capitalista que lo ayudaba a embarcarse en su órbita. Eloy Alfaro inaugura no sólo la vía férrea de Guayaquil a Quito, son varias otras que cruzarían regiones del país, con vistas a la extracción de los recursos naturales. Explotación de la naturaleza que ocurrirá con más fuerza en el siglo XX; aquello que ciertos autores denominan como colonialidad de la naturaleza. ${ }^{14}$

\footnotetext{
${ }^{12}$ CERVO, Amado Luiz. Hegemonia coletiva e equilíbrio: a construção do mundo liberal (1815-1871). In: SARAIVA, José Flávio Sombra. Relaçôes internacionais. Dois séculos de história. Entre a preponderâancia europeia e a hegemonia americano-soviética (1815-1947). Brasília: Ibri/Funag, 2001.

${ }^{13}$ Hablamos de recolonización, pues entendemos que el papel de España fue fundamental en ese proceso de reconquista cultural en el siglo XX, donde se reforzó la mentalidad colonial, basada en la cultura: religiosidad y lengua española. Sin olvidar el papel de Inglaterra y sus aliados (Hegemonía Colectiva) que cumplirán un papel fundamental en la nueva explotación de recursos naturales en la era republicana.

${ }_{14}$ "Colonialidad de la madre naturaleza y de la vida misma. La que encuentra su base en la división binaria naturaleza/sociedad, descartando lo mágico-espiritual-social, la relación milenaria entre mundos biofísicos, humanos y espirituales, incluyendo el de los ancestros, la que da sustento a los sistemas integrales de vida
} 
Las relaciones internacionales y la CONMEMoración del Primer Centenario de la Independencia en el ECUADOR, I 909. ENTRE LAS REFORMAS LIBERALES Y LAS COLONIALIDADES

\section{Gerson Galo Ledezma Meneses}

Los terratenientes y otros conservadores, sus esposas e hijas, junto con la Iglesia serían los encargados de promover la guerra contra los posibles cambios. Mujeres de elite controladas por la Iglesia, por el Estado liberal o conservador y por el modelo de familia patriarcal. ${ }^{15}$ Sectores que percibieron que las reformas liberales no deberían dar un giro a la izquierda o hacia un verdadero liberalismo. A ese proceso se unieron también los burgueses, quienes preferían reformas que los ayudase a controlar la mano de obra y a dar continuidad al sistema de dominación sobre cuerpos y mentes de los diferentes sectores inferiorizados: comunidades indígenas, afrodescendientes, mujeres negras, indias y pobres, pero que a la vez no estaban dispuestos a aceptar la invitación del Presidente Eloy Alfaro de unirse a favor de reformas más radicales.

Carlos Espinosa afirma que el anhelo de borrar la frontera interna que separaba a los blancos-mestizos de los indígenas era evidente entre los pensadores y legisladores vinculados al liberalismo radical de Eloy Alfaro ${ }^{16}$. Este proyecto quizás explique el por qué el radicalismo del presidente no sería posible. Retirar las fronteras entre blancos-mestizos e indígenas, pero también entre aquellos y los negros, significaba echar por tierra la colonidalidad de poder y dirigirse hacia un proceso de interculturalidad crítica, descolonial. ${ }^{17}$

\section{Ecuador en las relaciones internacionales en el siglo XIX}

Ecuador, como muchos otros Estados latinoamericanos, fue objeto de las ambiciones de potencias imperiales. España, Francia, Inglaterra, Brasil y Estados Unidos, entre 1830 y 1870, contemplaron la posibilidad de ejercer algún tipo de control o presencia en Ecuador y compitieron entre ellos por esa influencia. Los intereses de las grandes potencias frente al minúsculo Ecuador variaban según la misión imperial de las potencias, aunque tenían en común el hecho de que se enmarcaban en proyectos imperiales más amplios, en los que el

y a la humanidad misma". Ver: WALSH, Catherine. Interculturalidad, pluralidad y decolonialidad: las insusurgencias político-epistémicas de refundar el Estado. Tabula Rasa, v. 9, 2008, p. 131-152.

15 LEDEZMA MENESES, Gerson Galo. Cien años después: Estado-nación y sociedad conservadora. Atrapados en la colonialidad. Quito en la fiesta del Primer Centenario de la Independencia, 1909. En: ANALES DEL XVII CONGRESO NACIONAL DE HISTORIA DE COLOMBIA. Bogotá, 2016.

${ }^{16}$ ESPINOSA, Carlos. Historia del Ecuador. Barcelona: Lexus, 2010, p. 541.

17 "La interculturalidad (...) va mucho más allá del respeto, la tolerancia y el reconocimiento de la diversidad; señala y alienta, más bien, un proceso y proyecto social político dirigido a la construcción de sociedades, relaciones y condiciones de vida nuevas y distintas. Aquí me refiero no sólo a las condiciones económicas, sino también a ellas que tienen que ver con la cosmología de la vida en general, incluyendo los conocimientos y saberes, la memoria ancestral, y la relación con la madre naturaleza y la espiritualidad, entre otras. Por sí, parte del problema de las relaciones y condiciones históricas y actuales, de la dominación, exclusión, desigualdad e inequidad como también de la conflictividad que estas relaciones y condiciones engendran, es decir la "colonialidad" con sus cuatro ejes o potestades ya señalados". WALSH, Catherine. Interculturalidad, plurinacionalidad y decolonialidad: las insurgencias político-epistémicas de refundar el Estado. Tabula Rasa. Bogotá, v. 9, p. 131-152, jul./dic. 2008. 
Las relaciones internacionales y la CONMEMoración del Primer Centenario de la Independencia en el ECUADOR, I 909. ENTRE LAS REFORMAS LIBERALES Y LAS COLONIALIDADES

control sobre Ecuador era un trampolín para acceder a espacios más extensos. ${ }^{18}$ Notaremos que esos intereses ultrapasan esa fecha y que, en la conmemoración del I Centenario de la Independencia del Ecuador, en 1909, todavía se mantienen.

Recordemos que Ecuador, como proyecto de país, comienza su caminada a partir de 1830, pues antes hacía parte, junto con la antigua Capitanía de Venezuela y el extinguido Virreinato de la Nueva Granada, de la Gran Colombia, cuyo proyecto tuvo final con la muerte de su mentor Simón Bolívar. Pronto las realidades de su debilidad frente a sus vecinos se hicieron evidentes, así como su precariedad como Estado nación. Ante la indefinición de límites tanto al norte cuanto al sur — producto de esa reorganización territorial, creativa y confusa a la vez, que siguiera al colapso de la monarquía hispánica-, Ecuador tuvo que enfrentarse a la Realpolitiky, con ella, a la pérdida de su territorio a manos de sus dos vecinos, estando inclusive a punto de ser repartido entre ambos en $1860 .{ }^{19}$

El territorio ecuatoriano mostró ser de interés para las potencias europeas y después para Estados Unidos; punto estratégico como vía hacia el Amazonas, pero también al Pacífico por la localización allí de las Islas Galápagos. Entre 1830 y 1859, Francia había tenido relativamente poca influencia en Ecuador. La Flota Francesa del Pacífico Sur había realizado operaciones ocasionales para defender a ciudadanos franceses en ese país frente a supuestos abusos y había mostrado un interés esporádico en ocupar las Islas Galápagos. No fue hasta la época del presidente García Moreno que Francia tuvo participación en Ecuador, cuando éste le ofreció un protectorado sobre el país en 1859; en 1861, los diplomáticos franceses no desestimaron la propuesta. Entre las ventajas del protectorado identificadas por el encargado de negocios francés en Ecuador, en 1861, estaban el dominio del Pacífico Sur Occidental (presumiblemente a través de las Islas Galápagos) y el acceso al Amazonas. ${ }^{20}$

España invadió Perú, Islas Chincha, el 14 de abril de 1864; guerra en la que intervinieron, como aliados del país andino, Chile y posteriormente Bolivia y Ecuador. El 14 de enero de 1866 se firmó el Tratado de Alianza ofensiva y defensiva, celebrado entre las Repúblicas de Perú y Chile. El tratado invitaba a otras repúblicas sudamericanas a unirse para enfrentar a la escuadra española. Poco después, Bolivia y Ecuador se unieron a la alianza, aunque no llegaron a participar en la guerra. En previsión de un posible ataque español, Ecuador fortificó su puerto principal, Guayaquil. En 1866 España se retiró derrotada ${ }^{21}$ colocando

\footnotetext{
${ }^{18}$ ESPINOSA, Carlos. Ecuador se inserta en el sistema de Estados: las relaciones internacionales de Ecuador entre 1830 y 1870 , op. cit., p. 77-105.

${ }^{19}$ Idem.

${ }^{20}$ ESPINOSA, Carlos. Ecuador se inserta en el sistema de Estados: las relaciones internacionales de Ecuador entre 1830 y 1870 , op. cit., p. 77-105.

${ }^{21}$ HEREDIA, Edmundo. El império del guano. América Latina ante la guerra de España en el Pacífico. Córdoba: Alción, 1998; GARCÍA MARTÍNEZ, José Ramón. Combate de el Callao: restauración en el cementerio de Lima del mausoleo de los héroes del combate del 2 de mayo de 1866. Revista General de Marina, v. 266, p. 423440, abr. 2014; PONS MUZZO, Gustavo. Historia del Conflicto entre el Perú y España. Lima: Colegio San Julián, 1966; RODRÍGUEZ GONZÁLEZ, Agustín Ramón. La Armada Española, la Campaña del Pacífico, 1862-1871. España frente a Chile y Perú. Madrid: Agualarga Editores, 1999.
} 
Las relaciones internacionales y la CONMEMoración del Primer Centenario de la Independencia en el ECUADOR, I 909. ENTRE LAS REFORMAS LIBERALES Y LAS COLONIALIDADES

otros planes en práctica aprovechando la conmemoración de lo que para ella significaba el IV Centenario del "Descubrimiento" de América, en 1892.

La intención de Francia sobre América no terminó con el fusilamiento de Maximiliano, instaurado en México en la segunda mitad de la década de 1860; Napoleón III e intelectuales franceses intentaron crear el concepto de raza latina o raza francesa, tal como los espańoles de finales del siglo XIX con la raza ibérica o hispánica, ${ }^{22}$ de tal forma que se estableciera un clima de hermandad latina entre Francia y América, en oposición con el hispanismo (español) y posteriormente contra la cultura anglosajónica. De este modo, Francia estableció predominio cultural, no sólo desde esa época, ya que desde el Congreso de Viena de 18141815, cuando se estableció la Hegemonia Colectiva, entre Iglaterra, Francia, Prusia, Rusia y Austria, el país ya preponderaba ser el promotor de un proyecto civilizatorio que llegaría a todos los rincones del mundo. Así, llegada la época de la conmemoración del I Centenario de la Independencia, Francia siguió con sus propósitos de atraer a América Latina a su centro de irradiación cultural, París. Entonces, Francia pasa a formar parte de la vida diaria de las elites, y no sería raro que, a la época del Centenario, 1909, “(e)n el ámbito de lo cotidiano, invade el gusto por lo europeo y, en particular, lo francés: muebles, pianos, libros, balcones y rejas". ${ }^{23}$

Sin embargo, este país encontrará un fuerte rival, pues una vez derrotada en la guerra contra Perú y Chile en 1866, España vuelve a la Península Ibérica para planear una nueva reconquista, esta vez cultural, también bajo la invención de una raza ibérica: lengua española y religiosidad católica, en contrapunto a quien se convertirá, a partir de la guerra hispanoamericana, en 1899, en su peor enemigo, los Estados Unidos, país que rápidamente se había convertido en hegemónico e intentaba, a finales del siglo XIX, desbancar a Inglaterra de su sitio de privilegio sobre América Latina. Estados Unidos en guerra con España, se apoderó de Cuba y Puerto Rico, así como de Filipinas; forjó la separación entre Panamá y Colombia y a partir de 1903 empezó la construcción del Canal, pero al querer bases en su paso para Asia, las Islas Galápagos se convirtieron en objeto de deseo. De esa forma, nos es más claro verificar cuáles fueron los intereses de estos países, como España, Estados Unidos y Francia, en la fiesta conmemorativa del Centenario de la Independencia en Quito, 1909.

La presencia misteriosa y acechadora de los Estados Unidos en la fiesta del Centenario ecuatoriano, fue advertida por la prensa más representativa en Quito, la cual no dudó en publicar noticias que de América Central llegaban a la ciudad, sede del evento. En ese sentido, el diario El Comercio divulgó la noticia del periódico Diario de Nicaragua sobre

\footnotetext{
${ }^{22}$ Sobre el debate entre escritores españoles, franceses y latinoamericanos en la búsqueda por redefinir sus culturas en términos nacionales, hispanoaméricanos y latinos, y el establecimiento de las categorías raza hispana, raza ibérica, raza latina o raza francesa, puede consultarse a SEPÚLVEDA, Isidro. El sueño de la Madre Patria. Hispanoamericanismo y nacionalismo. Madrid: Fundación Carolina/Centro de Estadios hispánicos e Iberoamericanos, 2005.

23 CARCELÉN, Ximena; COMPTE, Florencio; DEL PINO, Inés. Ecuador en el Centenario de la Independencia. APUNTES, v. 19, n. 2, p. 236-255, 2006.
} 
la mala admósfera contra el gobierno de los Estados Unidos en esa nación. El periódico acusaba al país del Norte de querer adueñarse de todas las Repúblicas de América Central. ${ }^{24}$

\section{La Exposición Nacional}

Inspirado en las grandes exposiciones universales que se realizaron en Europa desde mediados del siglo XIX, Eloy Alfaro se convirtió en el entusiasta promotor y protector del Certamen Nacional. A su criterio, el fin de la Exposición no sería únicamente celebrar el Centenario patrio, sino también promover la industria nacional. Para dicho evento, el gobierno ecuatoriano envió invitación a varios países para que participaran en la muestra, de los cuales acudieron Estados Unidos, Francia, Bélgica, Japón, España, Italia, Colombia, Chile y Perú. A las dos de la tarde del 10 de agosto de 1909, aunque todavía inconclusas las obras, se inauguró formalmente el "Palacio de la Exposición" y el 8 de septiembre del mismo año, se abrieron sus puertas al público, de 8 a.m. a 9 p.m. ${ }^{25}$

\section{Estados Unidos en la Exposición Nacional}

En la Exposición Nacional, sin duda, uno de los países que más representación tuvo fue los Estados Unidos. El Pabellón Americano, decía la prensa, tendrá sitio reservado para nueve amplios Departamentos: de Estado, de Guerra, de Marina, de Justicia, de Tesoro, de Comercio y Asuntos de Trabajo, de Agricultura y de Correos. El Departamento de Estado exhibió copia de la Constitución y Declaratoria de Independencia. El de Guerra, un modelo de vapor; en la misma sección, había muestras del equipo de los soldados del Ejército de los Estados Unidos, varias armas pequeñas en uso actual, o de épocas pasadas, banderas y estandartes de innumerables clases, uniformes, etc. El Departamento de Marina, presentó seis modelos de buques de guerra; el de Justicia, cuadros y fotografías de las cárceles; el del Interior: dos escaparates con vistas de las Instituciones sostenidas por el Gobierno Federal para la educación de los indios, y muestras de los diferentes trabajos de estos. El Departamento de Correos ofreció una serie de trabajos, mapas e imágenes relativas a Colón y al "descubrimiento" de América. ${ }^{26}$ Debemos aclarar que

Estados Unidos adecuó un edificio en el norte de la ciudad — hoy edificio de la Orquesta Sinfónica Nacional—. En este conjunto, el Café Concert fue el edificio más novedoso, pues su

\footnotetext{
${ }^{24}$ El Comercio, Quito, jueves 15 de julio de 1909.

${ }^{25}$ HAHN, María Antonieta. El Palacio de la Exposición 1909-1989. Quito: Casa de la Cultura Ecuatoriana, 1989.

${ }^{26}$ El Comercio, Quito, 30 de julio de 1909.
} 
fachada muestra elementos art nouveau en su frente y constituye uno de los pocos ejemplos de este género en el país. ${ }^{27}$

Sí el gobierno de Estados Unidos estaba interesado en las Islas Galápagos, no dudaron en colocar a la vista de los representantes ecuatorianos, incluído el presidente Eloy Alfaro, su poder en armas de guerra; sus símbolos oficiales, sus instituciones de defensa. Había muestras de la Constitución, donde se encontraba su vocación de civilización y de justicia, que a lo largo del siglo XIX se había constituído como su Destino Manifiesto; los Estados Unidos estaban allí para mostrar su lado “justo” para con los indígenas, ya colocados, en ese país, en reservas, después de aniquilar a la mayoría de ellos. Por medio del Departamento de Correos, se mostraron imágenes de la invasión española, Cristobal Colón y lo que para ellos representaba el Descubrimiento de América. De esa forma, legitimaban lo que el discurso de ese momento manipulaba, la llegada de la civilización y el progreso. Progreso que de forma maravillosa hacía eco en las reformas liberales de Eloy Alfaro que, en ese momento, ya había inaugurado el tren de la Sierra, que llevaría todos los recursos naturales hacia el puerto de Guayaquil.

Los medios de comunicación dieron a conocer que los expositores nacionales fueron los más numerosos, lo que se entiende por la prisa del liberalismo en querer impulsar la explotación de recursos naturales y ponerlos a disposición de los invitados a la Exposición, especialmente los Estados Unidos y Francia. Pensamos que Inglaterra fue invitada, pero no sabemos los motivos por los cuales no compareció a la fiesta ecuatoriana, lo que demuestra la pérdida de espacio frente a los Estados Unidos. Tampoco se haría presente en las fiestas conmemorativas de los centenários de la Independencia en Argentina y Chile, en mayo y septimbre de 1910, respectivamente, sin embargo, en tales ocasiones, la ausencia fue justificada debido al luto por la muerte del Rey Eduardo VII, acaecida el 6 de mayo de ese año.

\section{Perú, Chile y Colombia en las relaciones con el Ecuador}

¿Cuáles fueron los intereses de Ecuador al invitar a Perú, Chile y Colombia a la conmemoración del I Centenario de la Independencia en Quito? Las alianzas que produjo la guerra de Espańa contra Perú no fueron duraderas, el descubrimiento de salitre y guano en las costas peruanas y la disputa por el mercado llevaron rápidamente a la guerra a Chile y Perú, y a la alianza entre éste y Bolivia, en la llamada Guerra del Pacífico, 1879-1883. Estados Unidos, aplicando su Doctrina de Monrroe se dispuso a arbitrar el desenlace de la guerra, con miedo de la intervención de potencias europeas. Sí bien Ecuador se mantuvo distante de

${ }^{27}$ CARCELÉN, Ximena; COMPTE, Florencio; DEL PINO, Inés. Ecuador en el Centenario de la Independencia, op. cit., p. 236-255. 
Las relaciones internacionales y la CONMEMoración del Primer Centenario de la Independencia en el ECUADOR, I 909. ENTRE LAS REFORMAS LIBERALES Y LAS COLONIALIDADES

los hechos, su simpatía estuvo a favor de Chile, pues con Perú ya existían querellas limítrofes; igualmente Argentina, quien cedió territorio al paso de tropas de los aliados contra Chile, ya que entre éste y el país austral también existían conflictos por las fronteras andina y en la Patagonia. Durante la Guerra del Pacífico, Chile se mantuvo alerta frente a la amenaza de Argentina posicionarse a favor de los Aliados. En ese sentido, se acercó a países como Brasil, Colombia y Ecuador. A este último quiso obligarlo a entrar a su favor, pues siempre se sintió un país superior que se relacionaba más con Europa que con sus vecinos andinos, especialmente.

En los años posteriores a la guerra, las relaciones de Chile hacia la región estuvieron fuertemente marcadas por los principios de la realpolitik, siguiendo los parámetros emanados desde Europa. En efecto, la acción de la política exterior chilena se sumó a los principios de los "Estados poderosos" en donde su voluntad se hacía respetar tanto por su peso diplomático, como por el uso de su capacidad militar. Para coronar esta situación, Chile adoptó el modelo militar prusiano, a partir de 1885 . Además, la modernización siguiendo el modelo europeo, estaba relacionada con otros ámbitos: la cultura, la ciencia, la educación. ${ }^{28}$

En 1895, Ecuador comenzaba a ser gobernado por el general Eloy Alfaro, que inició un proceso de modernización del Estado, partiendo por reestructurar sus Fuerzas Armadas: esencialmente su ejército, pero también su marina, buscando así dar término al proceso de inestabilidad política de su país, paralelamente a iniciar el despegue de su desarrollo económico, principalmente a partir de la exportación del Cacao a Europa. ${ }^{29}$

Eloy Alfaro, y sus reformas liberales, que le permitieron desarrollar el país desde la economía para insertarlo en el sistema-mundo capitalista, encontró en Chile su modelo referencial.

Eloy Alfaro por su parte, tomó conciencia de los peligros internacionales que acechaban al Ecuador y diseñó un plan de fortalecimiento estratégico del país, que incluía la modernización y profesionalización de las fuerzas armadas ecuatorianas y la construcción de una red de vías ferroviarias. En la ejecución de su plan, contrató una misión militar chilena, fundó el Colegio Militar, para la formación de oficiales; también creó la Escuela de Clases y los Cursos Militares de Aplicación, para la formación profesional de los suboficiales y la tropa. ${ }^{30}$

${ }^{28}$ TAPIA FIGUEROA, Claudio. Equilibrio de poder e influencia en las relaciones internacionales del Cono Sur: Chile y Ecuador, 1880-1902. Estudios avanzados, v. 12, p. 151-167, 2009.

${ }^{29}$ Idem.

${ }^{30}$ S/A. El cuasi conflicto armado ecuatoriano-peruano de 1910 (cuando los ecuatorianos atemorizamos al Perú) y el gral. Eloy Alfaro delgado presidente de la Republica del Ecuador fundador del ejército ecuatoriano de vanguardia. Quito, Ecuador, 14 de junio del 2008. Disponible en: <http://webnacionalistaecuador. s5.com/alfaro-casiguerra1910.htm>. Consulta el: 31 jul. 2016. 
De esta forma, entendemos la presencia de Chile, como uno de los invitados especiales a la conmemoración del I Centenario de la Independencia de Ecuador, especialmente a la Exposición Nacional, donde Chile tuvo papel especial.

En cumplimiento del Tratado de Guayaquil, en 1830 fue firmado en Lima el Protocolo Pedemonte-Mosquera, por el cual se fijó la línea de frontera. Con esta estructuración territorial, nació Ecuador en su vida independiente. Su jurisdicción abarcaba, en aplicación de los principios de la sucesión de los Estados, la que había tenido dentro de la Gran Colombia, el denominado Distrito del Sur, con los límites vigentes entre los virreinatos coloniales. La necesidad de consolidarse como Estado a través del reconocimiento internacional, llevó a que en 1832, Ecuador suscribiera su primer instrumento internacional: el Convenio NoboaPando, de amistad y comercio, precisamente con Perú. El Tratado advirtió la necesidad de celebrar un "Convenio de Límites entre los dos Estados". Después se suscribió el Tratado de Mapasingue que nunca entró en vigencia. Sin resolverse aún, la controversia fue nuevamente abordada en 1887 para someterla al arbitraje del Rey de Espańa. La indefinición de la materia arbitral, la demora en dar el fallo, resultó en el Tratado Herrera-García, en 1890, que a la postre, por no haber entrado en vigencia, no fue sino el instrumento que llevó a la inhibición del arbitraje español. Ante esta nueva situación, Perú retomó, con la aceptación de Ecuador, la tesis del arbitraje del rey de España en 1904. Las tensiones internas por la incertidumbre de llegar a una solución a través de este mecanismo, llevaron a las partes a las puertas de un conflicto armado, hecho que fue evitado por la intervención mediadora de Estados Unidos, Argentina y Brasil. ${ }^{31}$ Entendemos así, por qué el momento de conmemoración del Centenario de la Independencia ecuatoriano se hace tenso.

Siete años después de la conmemoración del Centenario de la Independencia en Quito, se firmó el Tratado Muñoz Vernaza-Suárez, que puso fin al litigio fronterizo entre Ecuador y Colombia; recordemos que aquella hizo presencia en la fiesta, como una de las invitadas especiales. Ecuador heredó de la disolución de la Gran Colombia problemas de frontera que lo llevó a la guerra de inmediato com Colombia, una vez fallecido el proyecto bolivariano. El 08 de diciembre de 1832, se firmó en Pasto un armisticio. El Tratado reconocía como límetes entre los dos países los de la Ley de División Territorial de 1824, incorporando, en consecuencia, a Nueva Granada las províncias de Pasto y Buenaventura. El 09 de julio de 1856, se suscribió en Bogotá un Tratado en que Ecuador y Colombia se comprometían a mantener los limites definidos en 1824 hasta que se suscribiera una convención que los definiera. Estas disposiciones estuvieron vigentes hasta 1905. Duante el gobierno de Gabriel García Moreno, Ecuador suscribió dos Tratados con Colombia, en los cuales se comprometía a conservar el Tratado de 1856, es decir, los de la Ley de División Territorial de

\footnotetext{
${ }^{31}$ CARRIÓN MENA, Francisco. El conflicto limítrofe con Perú como eje ordenador de la política exterior ecuatoriana (1942-1998). En: ZEPEDA, Beatriz (Comp.). Ecuador: relaciones internacionales a la luz del bicentenário. Quito: FLACSO, Sede Ecuador, 2009, p. 233-264.
} 
la Gran Colombia de 1824. A pesar de los esfuerzos por superar el problema, ambos países fueron a guerra, durante las presidencias colombianas de Julio Arboleda y Tomás Cipriano de Mosquera, quienes en diálogo con representantes peruanos pensaron en repartirse entre sí el territorio ecuatoriano. A fines de 1894, Colombia se adhirió al tratado de arbitraje Espinosa-Bonifaz, de 1887, donde Perú, Ecuador y Colombia concordaban en que el Rey de España decidiera las cuestiones de límites entre las tres Repúblicas. Sin embargo, finalmente, el tratado no fue ratificado por Ecuador. En 1904 se firmó un nuevo tratado entre Colombia y Ecuador, denominado Andrade-Betancourt, donde se ponía en manos del emperador de Alemania el destino de las fronteras; el cual no tuvo efecto toda vez que no fue consultado el monarca alemán. ${ }^{32}$ De esa forma, se aproximaba la fecha de la conmemoración del I Centenario de la Independencia de Ecuador, en 1909, y los problemas limítrofes entre los dos países solo tendrían resolución bajo el Tratado Muñoz Vernaza- Suárez, en 1916.

En el año del Centenario en Ecuador, El Ecuatoriano informaba sobre Colombia, de forma amigable; se atrevía a manifestar que, en ese país, después de los carnavales de la anarquía organizada con que este valiente pueblo escandalizó al mundo, otros aires soplaban. Sin embargo, y a pesar de que el golpe que las elites habían recibido con la separación de Panamá, lo que después había afligido al país, era la dictadura del General Reyes. ${ }^{33}$ El Comercio publicó una entrevista de Juan Ignacio Gálvez, ex consul de Colombia en Guayaquil quien, afirmó haberse desentendido de la política de Rafael Reyes. Al mismo tiempo, se le preguntó sobre el General Ramón González Valencia, candidato a la presidencia de Colombia al momento de la entrevista, electo en agosto de 1909, el mes del Centenario, y lo definía como un campesino honrado y creyente, soldado valeroso, pero sin ambiciones; enemigo, como todos los jefes sensatos liberales y conservadores, de todo movimento revolucionario en los momentos presentes. ${ }^{34}$

La prensa ecuatoriana conmemoró el día de la Independencia de Colombia, el 20 de julio de 1909. El Comercio calificaba al país vecino como una de las naciones más batalladoras de América del Sur; cansada de tantas revoluciones; después de haber ensayado, uno tras outro, régimenes de gobierno fundados en la idea liberal, en la conservadora y en la que dio en llamarse puramente nacional; después de haber experimentado, mucho más que culquiera otra nación del continente los males irremediables que producen las guerras civiles; después de una desmembración dolorosa; después de un transitorio marasmo, afirmaba la prensa, parecer que Colombia se propononía ir en busca de otros ideales, con otros medios de accion y con esfuerzos de un vigor renovado y generoso. Colombia, en especial, aseguraba

\footnotetext{
${ }^{32}$ ORDÓÑEZ, Hugo. La cuestión territorial ecuatoriana en el siglo XX. Del arbitraje Español al Enclave de Manta. Quito: Pudeleco Editores, s/f.

${ }^{33}$ El Ecuatoriano, Guayaquil, 27 de julio de 1909.

${ }^{34}$ El Comercio, Quito, 9 de julio de 1909.
} 
ese periódico, como pueblo joven, pero experimentado, no quería continuar en el mismo sendero de errores y desgracias que había recorrido durante un siglo, porque harta sabía que al fin de él solo se encuentraría con el fracaso, la ignominia, la pobreza y el descalabro. ${ }^{35}$

Sí consideramos que al momento de la celebración del Centenario de la Independencia los ecuatorianos esperaban la solución del litigio entre Colombia y Ecuador, y que el Tratado Muñoz Vernaza-Suárez lo haría en 1917, podemos entender las maniobras que el gobierno y la prensa ecuatoriana efectuaban en el sentido de crear un clima favorable a sus intereses. Para eso, la fiesta se convirtió en un vehículo para concretizar proyectos de esa naturaleza. Se hace notorio que la prensa y sus colaboradores, por las crónicas y noticias difundidas, conocían bien la historia de Colombia del Siglo XIX, pero más todavía, la de los últimos años, la guerra civil de los Mil Días y la llamada separación de Panamá, la cual, sabían también, ser una artimańa del gobierno de Estado Unidos, y, en ese sentido, transparece la solidaridad con el vecino país. Ecuador, por medio de la prensa, quería saber quiénes eran los políticos colombianos de turno; conocían la ditadura de Rafael Reyes, a la que abominaban, y existía la expectativa sobre quién sería el próximo presidente, pues de él dependía también el porvenir de las fronteras. Así, querían descifrar la figura del General González Valencia. El clima festivo muestra una Colombia desgastada, aniquilada, un país que seguramente no quería más guerras, y esto fue manipulado por la prensa. Ésta y el gobierno ecuatoriano sabían que los dos partidos tradicionales estaban fragilizados y sin ánimo de nuevos enfrentamentos. ${ }^{36}$

En la época del Centenario de la Independencia de Ecuador, el clima festivo fue totalmente tenso, pero no por el desenlace del problema fronterizo entre Colombia y el país andino, sino por causa del esperado dictamen del gobierno español que en 1910 emitiría fallo arbitral sobre el conflicto entre Ecuador y Perú. La incertidumbre afloraba en 1909, pues en ese año, también Perú y Bolivia esperaban fallo arbitral por parte de Argentina.

En América del Sur, los problemas se volvieron evidentes al momento de concretizar el utti possidetis de 1810, ya que a la hora de dos países sentarse a negociar y delimitar sus territorios, afectaron directamente las fronteras de terceros. Así sucedió con el Tratado del 23 de octubre de 1851 entre Perú y Brasil, donde se delimitaba el primer tramo de la frontera de ambos países: la línea Apaporis-Tabatinga y el río Yavarí.

La posición boliviana sostenía que este tratado definió toda la frontera entre Perú y Brasil, aceptando implícitamente que el territorio ubicado entre la naciente del Yavarí y la vaguada del Madeira era de su país, sustentando su tesis de la frontera con Perú, en la línea Yavarí-Inambari. Por el contrario, la postura peruana afirmaba que el acuerdo de 1851 únicamente definió una parte de la línea divisoria entre su país y Brasil, en los territorios conocidos de la Amazonia, admitiendo que fue un error no completar en ese momento la

\footnotetext{
${ }^{35}$ El Comercio, Quito, 20 de julio de 1909.

${ }^{36}$ Idem.
} 
Las relaciones internacionales y la CONMEMoración del Primer Centenario de la Independencia en el ECUADOR, I 909. ENTRE LAS REFORMAS LIBERALES Y LAS COLONIALIDADES

delimitación, tal como lo señaló su canciller José de la Riva Agüero, al finalizar los trabajos de la comisión peruano-brasileña. ${ }^{37}$

Por el Tratado de Ayacucho de 1863, comenzaron las discusiones limítrofes entre Brasil y Bolivia. El punto en disputa con Perú, fue la inclusión de los territorios ubicados entre el Yavarí y el Madera. La frontera entre el Imperio de Brasil y la República de Bolivia partiría del Río Paraguay hasta las nacientes del Río Verde; bajaría por este río hasta su encuentro con el Guaporé y por medio de este y del Mamoré hasta el Beni, donde comienza el Río Madera. De este río hacia el oeste seguiría la frontera por una paralela, salida de su margen izquierda en latitud sur 10 20', hasta encontrar el Río Javarí. El ministro de relaciones exteriores de Perú, José Antonio Barrenechea, protestó de este acuerdo ante la cancillería boliviana, formulando las reservas correspondientes. ${ }^{38}$

El 10 de octubre de 1891, Perú y Brasil celebraron en Río de Janeiro un tratado, obra del plenipotenciario peruano Guillermo Seoane y el canciller brasileño Justo Leite Chermont. En este acuerdo, se establecía la libre navegación del río Yavarí entre los dos Estados, además de otros convenios económicos. Sin embargo, Bolivia protestó contra este arreglo, salvando sus presuntos derechos sobre la margen izquierda del Yavarí. Tras otros fracasos, el plenipotenciario peruano Felipe de Osma y Pardo y el canciller boliviano Eliodoro Villazón suscribieron dos acuerdos el 23 y el 30 de septiembre de 1902, sobre demarcación y arbitraje en la cuestión de límites. La frontera peruano-boliviana se dividió en dos zonas: una fluvial y otra terrestre. Una comisión demarcadora debía fijar los hitos de la frontera de la zona terrestre, comprendida desde los territorios peruanos ocupados en ese momento por Chile hasta el río Suches. Sobre esta zona no había casi ninguna discusión, pues eran límites conocidos tradicionalmente. Por el tratado de arbitraje, se sometió a la decisión del gobierno argentino a quién debían pertenecer los territorios de la zona fluvial, de conformidad con las disposiciones y los títulos emanados del poder español, vigentes en 1810. ${ }^{39}$

El presidente argentino, José Figueroa Alcorta, emitió su laudo arbitral. La publicación de la sentencia dio lugar en Bolivia a manifestaciones en contra de Argentina y de Perú. Al mismo tiempo, la cancillería boliviana estaba dispuesta a no aceptar el fallo, presentó observaciones al árbitro, alegando que éste no había resuelto la cuestión conforme a los principios de derecho convenidos, sino conforme a la equidad. Entonces, Argentina rompió

\footnotetext{
${ }^{37}$ PORRAS BARRENECHEA, Raúl. Historia de los limites del Perú. Lima: Librería Francesa Científica y Casa Editorial E. Rosay, 1926; ZARCO, José. Cuestión de limites entre Bolivia y el Perú. La Paz: Impresora y Litografía Bolivianas, 1897; CASTELAR Y COBIÁN, Emilio. Nuestros límites con la República de Bolivia. Lima: Librería Escolar e Imprenta de E. Moreno, 1902.

${ }^{38}$ ZARCO, José. Cuestión de límites entre Bolivia y el Perú, op. cit.; CASTELAR Y COBIÁN, Emilio. Nuestros límites con la República de Bolivia, op. cit.

${ }^{39}$ PORRAS BARRENECHEA, Raúl. Historia de los limites del Perú, op. cit.; ZARCO, José. Cuestión de límites entre Bolivia y el Perú, op. cit.; CASTELAR Y COBIÁN, Emilio. Nuestros límites con la República de Bolivia, op. cit.
} 
sus relaciones diplomáticas. Asimismo, Perú y Bolivia estuvieron a punto de entrar en guerra. ${ }^{40}$

El presidente argentino Figueroa Alcorta emitió el fallo a favor de Perú, en detrimento de Bolivia, el 9 de julio de 1909, un mes antes de la conmemoración del Centenario en el Ecuador. Clima que empañó totalmente la efeméride, pues, como anotado, Ecuador esperaba ansiosamente el fallo del Rey de España, en la disputa limítrofe con Perú, y la pérdida de Bolivia a favor del vecino al sur provocaba una difícil expectativa entre los ecuatorianos. El Comercio notició los hechos como si se tratara del "conflito internacional del día”, a lo que añadió: "Cinco repúblicas en expectativa”, ya que el conflito y desenlace contaminaba no sólo a los dos países envueltos en la disputa, también a Argentina, que emitió el fallo, a Ecuador y Chile que se preparaban para tomar posición caso se desatara una guerra entre las partes. Otro subtítulo fue denominado así: "Um peligro inminente", llamando la atención para una posible guerra de carácter sudamericano, pues Brasil también cuestionó el fallo. "Mientras tanto, el gobierno brasileño acuerda igualmente, opornerse a la resolucion arbitral, porque considera que en ella se han desconocido los derechos que adquirió por compra sobre los territorios del Acre." ${ }^{11}$

Total: un verdadero conflicto internacional o, mejor dicho, continental, cuyo inminente peligro de guerra no se ocultará a nadie, sobre todo ahora que el gobierno del Perú y el del Argentina acaban de comunicar el ultimatum al gobierno boliviano, dándole apenas el perentorio plazo de treinta horas para la "definitiva". 42

Hubo levantantamientos en diferentes partes de Bolivia, como Oruro y Cochabamba; en aquellas ciudades fueron rasgadas las banderas y los escudos de los consulados de Peru y Argenrtina. Las sublevaciones se hicieron presentes también en la Paz. El Comercio condenó a los alzados y calificó los hechos de

Agresiva actitud de un populacho mal aconsejado, que, en un momento de ofuscación patriótica, se lanzaba en masa a insultar y vilipendiar a los representantes de dos pueblos amigos, haciendo caso omiso de las advertencias y súplicas de los ciudadanos prudentes y yéndose contra las fuerzas del Ejécito, que hacían lo posible para contener o dispersar a los manifestantes. ${ }^{43}$

El peródico en mención, aseguró que esos procedimientos, además de violentos, eran produto del instinto, sin consciencia de las consecuencias. Recordemos que las elites

\footnotetext{
${ }^{40}$ PAZ SOLDÁN, Carlos. El laudo argentino en la Cuestión de Limites entre el Perú y Bolivia y la actitud de Chile. Lima: Imprenta Liberal, 1909; PORRAS BARRENECHEA, Raúl. Historia de los límites del Perú, op. cit.

${ }^{41}$ El Comercio, Quito, 15 de julio de 1909.

${ }^{42}$ Idem.

${ }^{43}$ Idem.
} 
ecuatorianas permanecían bajo los efectos del proceso civilizador instaurado por Francia, $y$, en ese sentido, establecían una diferenciación entre civilizados y salvajes. Las turbas se entregaron al incendio y al pillaje, informó el diario. Las personas iba y venía en todas direcciones por las calles de la ciudad sin orden o concierto profiriendo los más groseros insultos a Perú y Argentina. En las calles, afirmaba, trabaron combates a pedradas, palos y tiros. Las fuerzas del ejército y seguridad habían sido impotentes "para contener la avalancha de gente que por todas partes afluía haciendo fuego con carabinas y revólveres, cometiendo actos de verdadero salvajismo" ${ }^{44}$ Fueron atacadas las legaciones del Perú y Argentina; los ministros huyeron. El ministro argentino con su esposa habría escapado milagrosamente, a la media noche, de ser asesinados por los revoltosos.

Después de consumado el ataque a las legaciones las hordas populares enfurecidas, sedientas de venganza y enloquecidas de la ira que produjo la decision del árbitro, acometieron contra los domicílios de los súbditos peruanos y argentinos y echaron a bajo las puertas a balazos y prendieron fuego. ${ }^{45}$

Los reclamos del gobierno de Argentina no se hicieron esperar.

Buenos Aires: se nota cierto movimiento en los cuarteles y parques militares de esta ciudad. Las versiones que circulan son que el Gobierno acordó en Consejo de Minsitros celebrado ayer, pedir enérgicamente reparaciones a Bolivia por los actos llevados a cabo en La Paz contra la vida de los súbditos argentinos y el Ministro Fonseca. En los círculos políticos y diplomáticos se dice que es inevitable el rompimiento de relaciones entre ambos países. ${ }^{46}$

Entre la renuncia del presidente Villazón en Bolivia y el pedido de altas explicaciones de los gobiernos argentino y peruano a las autoridades bolivianas, Perú estaba dispuesto a cumplir el laudo y a poner fin a su diferendo de límites con Bolivia, por lo que aceptó firmar un acuerdo de ejecución de fallo, en que se estipulaban algunos canjes de territorio en los adjudicados por el árbitro a ambas partes. El 17 de septiembre de 1909, el tratado fue firmado entre el ministro plenipotenciario de Perú, Doctor Solón Polo, y el canciller boliviano, Daniel Sánchez-Bustamante.

Más una vez, la prensa cumplió con sus objetivos a favor del gobierno ecuatoriano, al ponerse del lado de Perú y no de Bolivia. Cuando el presidente argentino Figueroa Alcorta emitió el Laudo, en julio, a favor de Perú, seguramente las delegaciones peruanas ya estaban haciendo sus maletas rumbo a la fiesta ecuatoriana en agosto de 1909. Era momento propicio para demostrarse los afectos y esperar que España, la madre patria, emitiera un fallo favorable

\footnotetext{
${ }^{44}$ Idem.

${ }^{45}$ Idem.

${ }^{46}$ Idem.
} 
Las relaciones internacionales y la CONMEMoración del Primer Centenario de la Independencia en el ECUADOR, I 909. ENTRE LAS REFORMAS LIBERALES Y LAS COLONIALIDADES

a uno de los dos países en litigio; y, en el caso de uno de los dos salir perjudicado, valerse de los lazos de amistad, reforzados en la fiesta del Centenario, para llegar a un acuerdo. Finalmente, España, una vez pasados los momentos auge de la conmemoración, el 24 de noviembre de 1910, informó que no daría el fallo en el conflicto entre Ecuador y Perú. ${ }^{47}$

\section{España en la fiesta en Quito}

La presencia de una España católica en Quito, —en cuyo poder había vuelto a concentrarse la dinastía Borbón, desde La Regeneración, en 1875, cuya base de gobierno era la Iglesia y el pasado colonial, ${ }^{48}$ y que ahora intentaba reconquistar culturalmente a América Latina, incluyendo a Ecuador-, explica las acciones tomadas contra el alfarismo, durante el Centenario, por parte de la Iglesia católica y las mujeres de elite; juntas dieron dura batalla contra las políticas liberales que querían hacer un reajuste de hegemonías, pero dentro del mismo patrón de poder. ${ }^{49}$

Además de la Exposición Internacional en la ciudad de Quito, hubo desfiles y discursos de las máximas autoridades; se inauguró un nuevo pedestal de la estatua del Mariscal Antonio José de Sucre. Nuevas esculturas no fueron realizadas, pues la principal ya había sido inaugurada en 1906: El Monumento a la Independencia, conocido también como Monumento a los Héroes del 10 de agosto de 1809, ubicado en el centro de la Plaza Grande. Fue inaugurado por el entonces presidente General Eloy Alfaro. Una de las figuras principales del monumento está representada por un león herido en huida; animal que en las representaciones mediterráneas significaba poder y realeza. Éste representa a España en el momento de las "independencias", huyendo de América para, supuestamente, nunca más volver. Sólo que, paradójicamente, el León vuelve a reconquistar América aprovechando la coyuntura internacional, su decadencia frente a Europa, la derrota en la guerra con Estados Unidos a finales del siglo XIX y las fiestas del Centenario a partir de 1909. "Raza ibérica", como la intelectualidad española la consideraba, cultura: religión y lengua española en la búsqueda de la reconquista ibérica en América y, quien sabe, la búsqueda por venganza contra los Estados Unidos, ya que España reencarnada seguiría viviendo en América. ${ }^{50}$

\footnotetext{
${ }^{47}$ ORDÓNEEZ, Hugo. La cuestión territorial ecuatoriana en el siglo XX. Del arbitraje Español al Enclave de Manta. Quito: Pudeleco Editores, s/f., p. 47.

${ }^{48}$ DE LA CUEVA MERINO, Julio. Clericalismo y movilización católica en la España de la Restauración. En: DE LA CUEVA MERINO, Julio; LÓPEZ VILLAVERDE, Ángel Luis (Coord.). Clericalismo y asociacionismo católico en España, de la Restauración a la Transición. Un siglo entre el palio y el consiliario. Cuenca: Ediciones de la Universidad de Castilla-La Mancha, 2005, p. 27-50.

${ }^{49}$ Ver: LEDEZMA MENESES, Gerson Galo. Cien años después: Estado-nación y sociedad conservadora. Atrapados en la colonialidad. Quito en la fiesta del Primer Centenario de la Independencia, 1909, op. cit.

${ }^{50}$ Sobre el proyecto de reconquista española en América, puede consultarse a GRANADOS, Aimer. Hispanismos, nación y proyectos culturales: Colombia y México: 1886-1921. Memoria \& Sociedad, v. 9,
} 
Las relaciones internacionales y la CONMEMoración del Primer Centenario de la Independencia en el ECUADOR, I 909. ENTRE LAS REFORMAS LIBERALES Y LAS COLONIALIDADES

En el evento de descubrimiento de la estatua del General Sucre, quien estrenaba nuevo pedestal, el General J. M. Sarati pronunció un discurso, como representante del Comité de la Exposición, en el cual hizo alusión a España. Así, el Cónsul de ese país, Manuel María Coll y Altabás, contestó con una improvisación "que arrancó de la concurrencia merecidísimos aplausos".

Manifestó el señor Coll la razón de que su Patria tomara parte en el Centenario, expresó que la noble Iberia, la gloriosa nación asombro del mundo, no podía morir porque tenía 17 hijas que serán las continuadoras de sus triunfos y la honra de su raza, rememoró la grandeza de su Pueblo que ha llenado con sus hechos la historia, desarrolló las más elevadas ideas de altruismo y confraternidad humana y de igualdad fraternal, hizo la apología de nuestros abolengos y sugestionó a sus oyentes con su palabra fácil, florida y llena de caluroso entusiasmo. Sinceros gritos de !viva España! se dejaron oír y el Presidente General Alfaro, terminado el elocuente discurso, abrazó emocionado al señor Cónsul. ${ }^{51}$

No debemos olvidar que las autoridades ecuatorianas aguardaban impacientes el resultado del Laudo que emitiría el parecer final, por parte del Rey de Espańa, como árbitro internacional, sobre el litigio entre Ecuador y Perú, desacuerdo limítrofe en tierras amazónicas. Los aplausos del presidente Eloy Alfaro son comprensibles pues él era un medio criollo, hijo de español, de madre nacida en la colonia americana en 1808. Hacer los debidos ajustes entre el paso de las regiones para el Estado nacional ecuatoriano requería dejar de lado la cultura francesa, impregnada en las elites latinoamericanas desde la segunda mitad del siglo anterior, y homogenizar la cultura nacional reforzando lo hispánico. Lo que significaba también, la negación de las innumerables culturas regionales. La cultura española servía para enfrentar al "enemigo" externo, los Estados Unidos, de cultura anglosajona. Pero servía a las elites ecuatorianas, y quiteńas principalmente, ahondar en la mentalidad conservadora y hacer frente a las políticas liberales de Alfaro.

El poeta y ensayista José M. Salaverria escribió en El Comercio, de Quito, el 21 de julio de 1909, a 19 días del Centenario ecuatoriano, el artículo titulado "España-América". Afirmaba que los españoles no habían hecho nada por justificar la historia de la dominación en América.

Ciertos escritores y pedagogos de América han hecho su labor, una labor que consiste en difamar a nuestros soldados, evangelizadores, governantes y jurisconsultos. Muchas escuelas americanas

n. 19, p. 5-18, jul./dic. 2005. FIGUERO SALAMANCA, Helwar Hernando. El imperio espiritual español: lengua, raza y religión (1930-1942). Anuario Colombiano de Historia Social y de la Cultura, n. 34, p. 5-18, 2007, p. 165-206. LEDEZMA MENESES, Gerson. Despertando o monstro: hispanismo na comemoração do I Centenário da Independência na Colômbia. História e Culturas, v. 1, n. 1, 2013.

${ }^{51}$ Las fiestas del Centenario. Día 10. Descubrimiento de la estatua del Gran Mariscal. La Prensa, Quito, 10 de agosto de 1909. 
estan llenas de lugares comunes virulentos, en donde los niños aprenden bien pronto a odiar al antepasado español. (...) La barbarie española, el fanatismo español, la crueldade espańola; estos son tópicos y lugares comunes en la literatura intima de América (...). ${ }^{52}$

Hizo un llamado a la unión, para que los numerosos componentes del conjunto hispánico se mezclasen y se buscasen. "Todo esto se puede conseguir por medio del idioma catellano", afirmaba. "Y aun puede conseguirse algo parecido a lo que llaman imperialismo anglosajón'. Nosotros podemos hablar sin ninguna timidez del 'imperialismo catellano'. Puesto que andando un siglo de fecha hablarán en castellano más de 200 millones de personas."

La rivalidad no era sólo con Francia, sino claramente también con los Estados Unidos. La pelea era territorial, pero principalmente de caracter cultural para España. Literatos, como Blasco Ibáñez, se deslumbraron con América. El 10 de agosto de 1909, el día central de la conmemoración se publicó en El Comercio el siguiente texto así titulado: "Porvenir de América". Entendíase allí que España sobreviviría por medio de un cuerpo ajeno, reencarnada en América. El único camino que le quedaba al país ibérico era la realización de una metamorfosis, para poder volver a sentir las glorias que había perdido decididamente en el siglo anterior. Se atrevía a asegurar que América debía a España gratitud, por el esfuerzo doloroso de haberla amamantado durante tres siglos. Pensaba que el decaimiento de España era explicado por algunos con las guerras civiles, el fanatismo religioso y otras causas interiores.

No: España está enferma simplemente de tanto parir y criar. Es una hembra que ha dado a luz 18 hijos, todos con vida fuerte y su situacion es semejante a la de esas madres prolíferas, débiles y enfermizas, a las que ningun médico puede diagnosticar la dolencia. Es simplemente anémica, exceso de creación, pérdida de fuerzas por haberlas transmitido con creces a los hijos. Pero la noble matrona, enferma y agotada, sonríe con sonrisa de madre, viendo a su prole robusta de futuros gigantes, sangre de sus venas, músculos de sus carnes, que crecen y crecen, mientras llega el momento de dominar al mundo. ${ }^{53}$

La prensa justificaba la Independencia para poder destacar la presencia española en el Centenario, inclusive también la invasión de 1492, pues, como lo planteaba Blasco Ibáñez, los conquistadores habían luchado contra la naturaleza y no contra los índios. Una lucha para introducir la civilización en medio de la barbarie indígena. El mismo día de la fiesta central, La Prensa, de Quito, con este título: “Quito, Luz de América, 1809”, publicó un escrito de Manuel J. Calle. En él afirmaba que las luchas por la independencia se habían trabado contra Fernado VII y no contra España. Termina el texto preguntándose lo siguiente: ¿Qué

\footnotetext{
${ }^{2}$ SALAVERRIA, José M. España-América. El Comercio, Quito, 21 de julio de 1909.

${ }^{53}$ El Comercio, Quito, 10 de agosto de 1909.
} 
fue la emancipación hispanoamericana? ¿Sería la rebelión de los súbditos americanos contra la legitimidad de su legítimo soberno? - "No: fue la despedida que hace del hogar paterno el hijo, que, habiendo llegado ya a la mayor edad, sale a constituir hogar independiente, para perpetuar la família solariega, dando nuevo lustre al blasón de su heredada nobleza" ${ }^{54}$ Respuesta que una vez más coloca en el escenario la metáfora de la família, tal como fue colocada durante la época colonial y las luchas de los criollos por la Independencia.

\section{Al final}

Destacamos la figura de Eloy Alfaro, preocupado por un cambio radical en medio de un clima conservador y liberal no apto para enfrentar la revolución alfarista. Ésta se destinaría a concretizar el Estado nación, sacándolo de la provincia para conectarlo con el sistema-mundo capitalista colonial/moderno y patriarcal. En ese sentido, las elites quiteñas y ecuatorianas no entendieron que el giro pretendido por Alfaro no afectaba totalmente el modelo de sociedad, pues al fin y al cabo el sitema capitalista o el Estado liberal continuaría racializando e inferiorizando a los negros, indígenas y mujeres para una mejor explotación. De tal modo, entendemos la búsqueda por solucionar las pendencias limítrofes con los vecinos; la puesta en marcha de mecanismos que centralizaran al ejército a partir de un eje dominante, la ciudad de Quito y la provincia de Guayaquil; regiones que se conectarían con las províncias para, definitivamente, someter a las regiones que no habían permitido la visibilidad del Estado. En ese objetivo, su alianza con Chile era significativa, pero también sus relaciones con Europa y Estados Unidos, ya que juntos proyectarían un Estado nación fuerte, controlador no apenas en la economía, sino también en los cuerpos y en las mentes. Para eso, su alianza con España era imprescindible. Finalmente, Alfaro es preso en Guayaquil, en 1912, cuando pretendía de nuevo la presidencia; fue llevado a Quito y allí fue expuesto ante la sociedade quiteńa que le cobraría caro su osadía de transformación más allá de lo permitido por la sociedad conservadora ecuatoriana. El domingo 28 de enero de 1912, "Quito se convirtió en escenario del crimen que una turba fanática consumó contra el general Eloy Alfaro Delgado, líder del liberalismo ecuatoriano, así como de su hermano Medardo, su sobrino Flavio, el periodista Luciano Coral y los militares Manuel Serrano Renda y Ulpiano Páez." 55

La muerte de Alfaro dio inicio a la creación de un mito heróico por parte de la literatura y la historiografía liberal principalmente. El ex presidente se convirtió en el eje catalizador de la realización de la revolución inconclusa; ese imaginario revolucionario nutrió la mente

\footnotetext{
${ }^{54}$ Idem.

${ }^{55}$ El asesinato de Eloy Alfaro Delgado. El Universo, 28 de enero de 2010. Disponible en: <http://www.eluniverso.com/2010/01/28/1/1445/asesinato-eloy-alfaro-delgado.html>. Consulta en: 2 ago. 2015.
} 
de indígenas y otros sectores de la sociedad hasta conectarse con el Segundo Centenario de la Independencia, en 2009, justo cuando nuevos aires soplaban en el escenario político del país, y así entonces se habló de una revolución ciudadana que, de una u otra manera, evocaría a Alfaro y las reformas liberales de 1895 a 1911. Cuando Rafael Correa fue elegido Presidente en 2006 y se instauró la Asamblea Constituyente en 2007, la cual tuvo como principal objetivo la redacción de una nueva Constitución, el sitio escogido para tales fines fue un pequeño pueblo de la provincia costeńa de Manabí llamado Montecristi. La elección de este sitio tuvo como propósito, asociar la "nueva revolución ciudadana", del gobierno de Correa, con el lugar de nacimiento de Eloy Alfaro, también recordado como el viejo luchador. ${ }^{56} \mathrm{La}$ exploción del movimiento indígena ecuatoriano, desde la década de 1990 hasta la actualidad ha nutrido la historiografía que busca las raíces históricas de la así llamada agitación indígena, en las reformas liberales de Eloy Alfaro. ${ }^{57}$

\section{Bibliografía}

\section{Fuentes primarias:}

El Comercio, Quito, 3 de julio de 1909.

El Comercio, Quito, 9 de julio de 1909.

El Comercio, Quito, 15 de julio de 1909.

El Comercio, Quito, 20 de julio de 1909.

El Comercio, Quito, 30 de julio de 1909.

El Comercio, Quito, 10 de agosto de 1909.

El Ecuatoriano, Guayaquil, 27 de julio de 1909.

El Universo, 28 de enero de 2010. El asesinato de Eloy Alfaro Delgado. Disponible en: <http://www.eluniverso.com/2010/01/28/1/1445/asesinato-eloy-alfaro-delgado.html>. Consulta en: 2 ago. 2015.

La Prensa, Quito, 10 de agosto de 1909. Las fiestas del Centenario. Día 10. Descubrimiento de la estatua del Gran Mariscal.

\section{Fuentes secundarias}

ALBORNOZ PERALTA, Oswaldo. Ecuador: luces y sombras del liberalismo. Quito: El Duende, 1989.

\footnotetext{
${ }^{56}$ Sobre tal asunto puede consultarse a RAMOS, Juan G. Crónica de una muerte pasada: Eloy Alfaro, Vargas Vila y "La muerte del cóndor" como texto híbrido modernista. Textos Híbridos, v. 3, n. 1, jul. 2013.

${ }^{57}$ Tal como lo reconoce PRIETO, Mercedes. Liberalismo y temor. Imaginando los sujetos indígenas en el Ecuador postcolonial, 1895-1950. Quito: Abya Yala, Flacso, 2004.
} 
Las RelaCiones internacionales y la CONMEMoración del Primer Centenario de la Independencia en el ECUADOR, I 909. ENTRE LAS REFORMAS LIBERALES Y LAS COLONIALIDADES

ARRIGHI, Giovanni; SILVER, Beverly. Caos e governabilidade no moderno sistema mundial. Rio de Janeiro: Contraponto/UFRJ, 2001.

ARRIGHI, Giovanni. O longo século XX: dinheiro, poder e as origens de nosso tempo. Rio de Janeiro: Contraponto; São Paulo: Unesp, 1995.

AYALA MORA, Enrique. Resumen de historia del Ecuador. 4. ed. Quito: Corporación Editora Nacional/Universidad Andina Simón Bolívar, 2012.

. De la revolución alfarista al régimen oligárquico liberal, 1895-1925. En: AYALA MORA, Enrique (Ed.). Nueva Historia del Ecuador, v. 9. Quito. CEN-Grijalbo, 1988.

. Historia, tiempo y conocimiento del pasado. Estudio sobre periodización general de la historia ecuatoriana: una interpretación interparadigmática. Quito: Universidad Andina Simón Bolívar, 2014.

BETHELL Leslie. O Brasil e a ideia de "América Latina" em perspectiva histórica. Estud. Hist., Rio de Janeiro, v. 22, n. 44, jul./dec. 2009.

CARCELÉN, Ximena; COMPTE, Florencio; DEL PINO, Inés. Ecuador en el Centenario de la Independencia. APUNTES, v. 19, n. 2, p. 236-255, 2006.

CARRIÓN MENA, Francisco. El conflicto limítrofe con Perú como eje ordenador de la política exterior ecuatoriana (1942-1998). En: ZEPEDA, Beatriz (Comp.). Ecuador: relaciones internacionales a la luz del bicentenário. Quito: FLACSO, Sede Ecuador, 2009, p. 233-264.

CASTELAR Y COBIÁN, Emilio. Nuestros límites con la República de Bolivia. Lima: Librería escolar e Imprenta de E. Moreno, 1902.

CUEVA, Agustín. El processo de dominación política en Ecuador. Quito: Voluntad, 1973.

DUROSELLE, Jean-Baptiste. Todo império perecerá. Teoria das relaçôes internacionais. Tradução de Ane Lize Spaltemberg de Seiqueira Magalhães. Brasília: Ed. UnB, 2000.

DUSSEL, Enrique. 1492: El encubrimiento del Otro. Hacia el origen del "mito de la Modernidad". La Paz: Facultad de Humanidades y Ciencias de la Educación/Plural Editores, 1994.

ESPINOSA, Carlos. Ecuador se inserta en el sistema de Estados: las relaciones internacionales de Ecuador entre 1830 y 1870. En: ZEPEDA, Beatriz (Comp.). Ecuador: relaciones internacionales a la luz del bicentenário. Quito: FLACSO, Sede Ecuador, 2009, p. 77-105. ESPINOSA, Carlos. Historia del Ecuador. Barcelona: Lexus, 2010, p. 541.

GARCÍA MARTÍNEZ, José Ramón. Combate de el Callao: restauración en el cementerio de Lima del mausoleo de los héroes del combate del 2 de mayo de 1866. Revista General de Marina, v. 266, p. 423-440, abril 2014.

GIMENO GÓMEZ, Ana. Ecuador y España a través del trato del general Flores con la Familia Real española: testimonios epistolares. En: ZEPEDA, Beatriz (Comp.). Ecuador: 
Las relaciones internacionales y la CONMEMoración del Primer Centenario de la Independencia en el ECUADOR, I909. ENTRE LAS REFORMAS LIBERALES Y LAS COLONIALIDADES

relaciones internacionales a la luz del bicentenário. Quito: FLACSO, Sede Ecuador, 2009, p. 107-147.

HAHN, María Antonieta. El Palacio de la Exposición 1909-1989. Quito: Casa de la Cultura Ecuatoriana, 1989.

HEREDIA, Edmundo. El império del guano. América Latina ante la guerra de España en el Pacífico. Córdoba: Alción, 1998.

HURTADO, Oswaldo. El poder politico en el Ecuador. 17. ed. Quito: Planeta, 2007.

LEDEZMA MENESES, Gerson Galo. Cien años después: Estado-nación y sociedad conservadora. Atrapados en la colonialidad. Quito en la fiesta del Primer Centenario de la Independencia, 1909. En: ANALES DEL XVII CONGRESO NACIONAL DE HISTORIA DE COLOMBIA. Bogotá, 2016.

MORALES MANZUR, Juan Carlos. Argentina, Gran Colombia y Ecuador. Siglo XIX: entre la monarquía y la república. Revista de Artes y Humanidades UNICA, v. 9, n. 22, p. 13-41, mayo/ago. 2008. Universidad Católica Cecilio Acosta Maracaibo, Venezuela.

ORDÓNEEZ, Hugo. La cuestión territorial ecuatoriana en el siglo XX. Del arbitraje Español al Enclave de Manta. Quito: Pudeleco Editores, s/f.

PAREJA DIEZCANSECO, Alfredo. Breve historia del Ecuador. Quito: Libresa, 1994.

PAZ SOLDÁN, Carlos. El laudo argentino en la Cuestión de Limites entre el Perú y Bolivia y la actitud de Chile. Lima: Imprenta Liberal, 1909.

PONS MUZZO, Gustavo. Historia del Conflicto entre el Perú y España. Lima: Colegio San Julián, 1966.

PORRAS BARRENECHEA, Raúl. Historia de los límites del Perú. Lima: Librería Francesa Científica y Casa Editorial E. Rosay, 1926.

QUIJANO, Aníbal. Colonialidad del poder y clasificación social. En: CASTRO-GÓMEZ, Santiago; GROSFOGUEL, Ramón (Ed.). El giro decolonial. Reflexiones para una diversidad epistémica más allá del capitalismo global. Bogotá: Siglo del Hombre Editores/Universidad Central/Instituto de Estudios Sociales Contemporáneos y Pontificia Universidad Javeriana/ Instituto Pensar, 2007.

GROSFOGUEL, Ramon. La descolonización de la economía politica. Cuaderno de Investigación. Bogotá: Universidad Libre, Bogotá, 2010.

RENOUVIN, Pierre; DUROSELLE, Jean-Baptiste. Introducción a la historia de las relaciones internacionales. Madrid: FCE, 2000.

RIVADENEIRA MORENO, Katerine Elisa. Monitoreo de editoriales y artículos de opinión y la imagen que proyectan del presidente Rafael Correa. Estudio de caso: Diario El Comercio Abril 2009. Tesis (licenciada en Comunicación Social) —Universidad Politécnica Salesiana, Sede Quito, 2013. 
RODRÍGUEZ GONZÁLEZ, Agustín Ramón. La Armada Española, la Campaña del Pacífico, 1862-1871. España frente a Chile y Perú. Madrid: Agualarga Editores, 1999. RODRÍGUEZ, Linda Alexandre. Política y poder en el Ecuador, 1830-1925. Quinto Centenario 7, Madrid: Universidad Complutense, 1985, p. 36. Disponible en: <http:// revistas.ucm.es/index.php/QUCE/article/view/QUCE8484110017A/1836>. Consultado el: 1 ago. 2015.

S/A. El cuasi conflicto armado ecuatoriano-peruano de 1910 (cuando los ecuatorianos atemorizamos al Perú) y el gral. Eloy Alfaro delgado presidente de la Republica del Ecuador fundador del ejército ecuatoriano de vanguardia. Quito, Ecuador, 14 de junio del 2008. Disponible en: <http://webnacionalistaecuador.s5.com/alfaro-casiguerra1910.htm>. Consulta el: 31 jul. 2016.

SALAVERRIA, José M. España-América. El Comercio, Quito, 21 de julio de 1909.

TAPIA FIGUEROA, Claudio. Equilibrio de poder e influencia en las relaciones internacionales del Cono Sur: Chile y Ecuador, 1880-1902. Estudios avanzados, v. 12, p. 151-167, 2009.

WALSH, Catherine. Interculturalidad, plurinacionalidad y decolonialidad: las insurgencias político-epistémicas de refundar el Estado. Tabula Rasa. Bogotá, v. 9, p. 131-152, jul./dic., 2008.

WALLERSTEIN, Immanuel. Análisis de Sistemas Mundo. Una Introducción. México: Siglo XXI, 2006.

. O sistema mundial moderno. V. II: o mercantilismo e a consolidação da economiamundo europeia, 1600-1750. Porto: Afrontamentos, 1980.

. El moderno sistema mundial (III). La segunda era de gran expansión de la economíamundo capitalista, 1730-1850. Madrid: Siglo XXI de España, 2010.

. O sistema mundial moderno. V. I: a agricultura capitalista e as origens da economiamundo europeia no século XVI. Porto: Afrontamentos, 1974.

ZARCO, José. Cuestión de límites entre Bolivia y el Perú. La Paz: Impresora y Litografía Bolivianas, 1897. 